\title{
SENSITIVITY OF A MATHEMATICAL MODEL USED TO OPTIMIZE REVENUE IN A PREDATION-COMPETITION FARMING ENVIRONMENT
}

\section{J Swart}

Department of Mathematics and Applied Mathematics, University of Natal, Pietermaritzburg, 3200 South Africa.

\begin{abstract}
Sheep farmers in the Cape Midlands region of South Africa frequently sustain stock losses through predation by caracal lynx. Further losses are incurred when hyrax compete with sheep for available pasture. Hyrax constitute the natural prey for lynx with the result that culling either hyrax or lynx has complicated feedback effects. In order to investigate the spill-over problems from the natural predator-prey system on farming revenue, a differential equations model was previously formulated, comprising the sectors Hyrax, Lynx, Sheep, Pasture and Revenue and an optimization procedure was used to determine the optimal culling rate policy for farmers. The purpose of this paper is to investigate the numerical, behavioural and policy sensitivity of this model to parameter uncertainty.
\end{abstract}

\section{INTRODUCTION}

The sheep farming region of the Cape Midlands, South Africa, includes many areas too rugged for agricultural exploitation. The hyrax Procavia capensis and lynx Felis caracal that abound in most of these wilderness areas pose a problem to the farmer. When the hyrax population exceeds the carrying capacity of the wilderness areas, the hyrax encroach upon farming land and consume pasture in competition with sheep. Although hyrax constitute the principal food of lynx [Fairall 1980, Grobler 1981] farmers sustain further losses to their flocks through lynx predation.

A mathematical model comprising Sheep, Hyrax, Lynx, Pasture and Revenue was 
previously formulated to investigate the general consequences of different culling strategies simed at curbing lynx predation of sheep and hyrax competition with sheep [Swart \& Hearne 1989]. To keep the model simple, the populations were divided into a limited number of age classes. The different groups, their initial values and the rates determining their levels are shown in table 1 . A region of 200000 ha was chosen as the model boundary.

\begin{tabular}{|c|r|r|l|l|}
\hline Group & Initial Value & Age (yrs) & \multicolumn{1}{|c|}{ Recruitment } & \multicolumn{1}{|c|}{ Losses } \\
\hline HJ & 350000 & $0-1$ & Births & Maturation, Death, Predation \\
HF & 262500 & $1+$ & Maturation & Death, Culling, Predation \\
HM & 262500 & $1+$ & Maturation & Death, Culling, Predation \\
\hline LJ & 200 & $0-1$ & Births & Maturation, Death \\
LF & 300 & $1+$ & Maturation & Death, Culling \\
LM & 300 & $1+$ & Maturation & Death, Culling \\
\hline SJ & 80670 & $0-2$ & Births & Maturation, Death, \\
& & & & Predation, Culling \\
SF & 75567 & $2+$ & Maturation & Death, Culling \\
SM & 50379 & $2+$ & Maturation & Death, Culling \\
\hline
\end{tabular}

Table 1.

Population Groups. Symbols beginning with H, L and S indicate Hyrax, Lynx and Shheep, respectively. The last letter of each symbol refers to Luveniles, Eemales and Males.

It is assumed that emigration from this region is approximately equal to immigration. The numbers involved in migration are in any case likely to be insignificantly small compared with the population of this large region. Due to practical difficulties hyrax and lynx juveniles are not subjected to culling [Fourie 1983]. Although lynx do sometimes kill adult sheep, predation of sheep is confined to the juvenile group (lambs) in the model.

As a grazer, prey item or predator a juvenile does not have the same effect on the system as an adult. The juveniles were converted to equivalent adult units and added to the corrresponding adults to yield the quantities [initial values in brackets]: 


$$
\begin{aligned}
& \text { HUT }=\text { Hyrax Units Total [700000] } \\
& \text { LUT = Lynx Units Total [700] } \\
& S S U=\text { Small Stock Units (sheep) }[180000]
\end{aligned}
$$

When there is insufficient hyrax for the lynx to sustain their natural diet, lynx fecundity and juvenile mortality are adversely affected. Furthermore when the Prey Abundance $(P A)$ is low, lynx will supplement their diet by killing lambs. When the hyrax density $(H D)$ exceeds the carrying capacity of the wilderness area, hyrax spill over onto farming land and affect the rate at which pasture is grazed.

Revenue is obtained from mutton sales (directly proportional to sheep culling), wool sales (proportional to the number of sheep in each cohort) and interest on revenue. Loss of revenue is incurred through lynx culling, hyrax culling and veterinary and other costs (directly proportional to the number of sheep). Certain other fixed costs were not included as they do not reveal anything about the relative merits of a culling strategy. Culling of hyrax and lynx is by means of shooting; trapping and poisoning are not practised. It is likely that culling costs of hyrax and lynx per head will rise at lower population densities, resulting from higher culling rates, and this has been taken into account in the model.

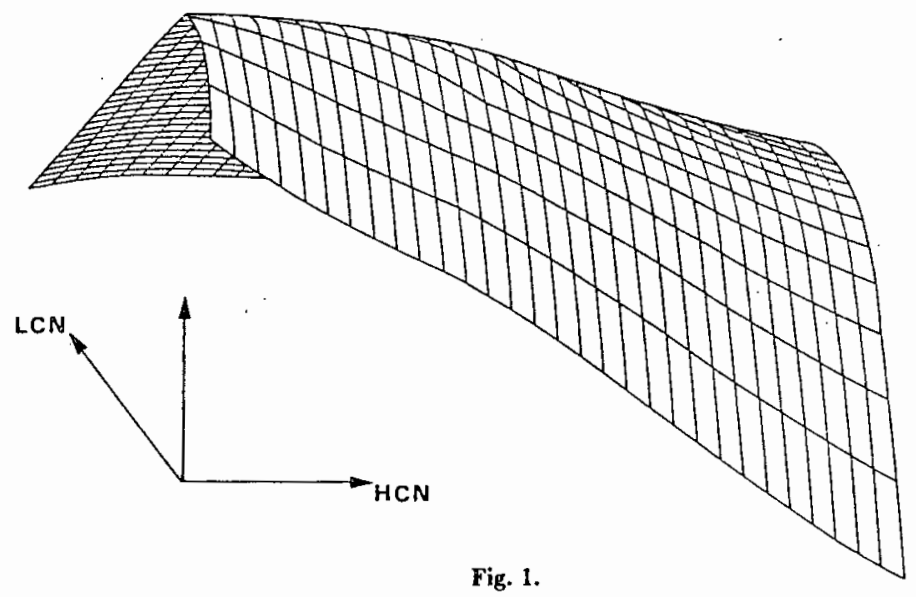

The Total Revenue surface 
The appendix to this article includes the model equations and a symbol name listing, but for a detailed formulation of the model, the reader is referred to Swart \& Hearne [1989]. In the above article it was established that simultaneous culling of hyrax and lynx was necessary for reasonable profitability. A simple objective function, incorporating the revenue generated over the simulation period as well as the stock position at the end of this period, was set up to measure the relative merits of various strategies. An optimization procedure was used to obtain optimal culling rates to maximize the "Total Revenue" so obtained.

In figure 1 the graph of Total Revenue is plotted against Hyrax Culling Normal ( $H C N$ ) and Lynx Culling Normal ( $L C N)$ to illustrate the nature of the surface to be maximized. The optimal annual culling rates for hyrax and lynx were found to be 0.31 and 0.33 respectively.

The differential equations describing the model were solved numerically and simulations were carried out on a Sperry 1100/71 computer using FORTRAN 77.

\section{PARAMETER SENSITIVITY ANALYSIS}

The model is described by a system of non-linear first order differential equations of the form

$$
d x_{i} / d t=f_{i}(x, p)
$$

where $x=\left(x_{1}, \ldots, x_{n}\right)$ and $p=\left(p_{1}, \ldots, \dot{p_{m}}\right)$ are the state variables at time $t$ and the parameters of the system respectively, and we now investigate the sensitivity of the model to parameter uncertainty. Several relationships in the model are described non-linearly and it is highly desirable to include the sensitivity of the model to changes in functional relationships [Swart 1990]. For this reason, table functions were specified using the three parameter analytical form [Uys 1984]:

where

$$
\text { for } \begin{aligned}
A>1,0<B & <1 \text { and } t, s>0 \text { we define } \\
f(\mathrm{~A}, \mathrm{~B}, \mathrm{~s}, \mathrm{t}) & =\mathrm{A} /\left[1+\mathrm{E} \cdot \exp \left(-\mathrm{C} . \mathrm{t}^{\mathrm{s}}\right)\right] \\
E & =(A / B)-1 \\
C & =\ln [E /(A-1)] .
\end{aligned}
$$

The table functions used in certain rate equations in the model were defined as follows:

$$
\begin{aligned}
H J D M & =f(1.7,0.5,1.5, \text { HDA }) \\
L P M & =f(2.0,0.1,0.6, P A) \\
L F M & =f(1.5,0.7,1.5, P A A) \\
G M & =f(2.0,0.1,1.0, P A I)
\end{aligned}
$$




$$
\begin{aligned}
& S F M=f(2.0,0.01,0.5, G M A) \\
& H F M=1 / f(2.5,0.625,2.5, H D A) \\
& L J D M=1 / f(1.43,0.71,2.0, P A A) \\
& S J D M=1 / f(1.66,0.335,3.5, G M A) .
\end{aligned}
$$

The functions above refer respectively to Hyrax Juvenile Death Multiplier, Lynx Predation Multiplier, Lynx Fecundity Multíplier, Grazing Multiplier, Sheep Fecundity Multiplier, Hyrax Fecundity Multiplier, Lynx Juvenile Death Multiplier and Sheep Juvenile Death Multiplier. As the full impact of a change in variables such as $H D$ and $P A$ are not always felt immediately, exponentially smoothed versions of these variables (HDA and $P A A$ ) occur as function arguments above. The Pasture Availability Index (PAI) measures the relative abundance of pasture and $G M A$ is a smoothed version of the Grazing Multiplier (GM). The graphs of two typical functions $H J D M$ and $S J D M$ are shown in figure 2 below.

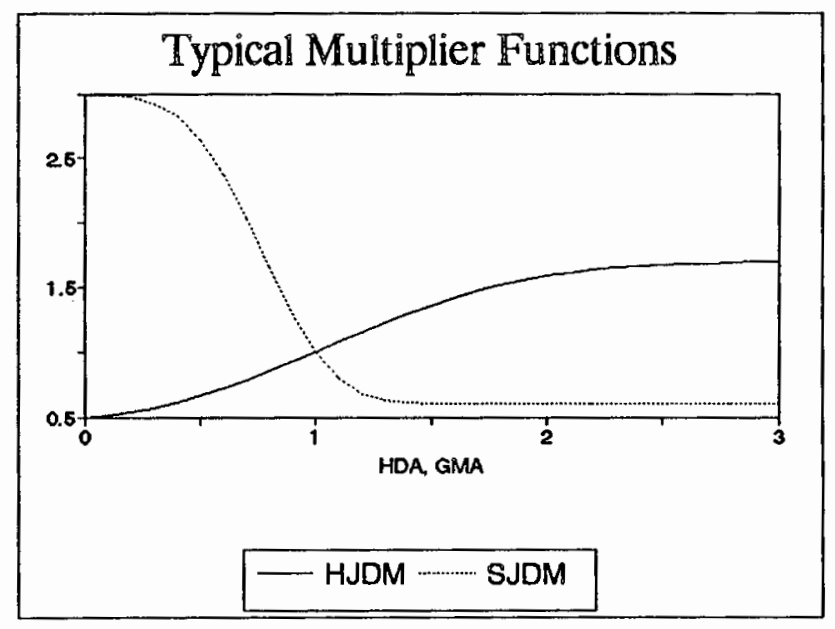

Fig 2.

Hyrax Juvenile Death Multiplier as a function of HDA and Sheep Juvenile Death Multiplier as a function of GMA.

By using the analytic specification above, each table function is completely determined by three parameters $A, B$ and $s$. Uncertainty in the model can therefore be tested by analyzing parameter uncertainty only. "In the parameter sensitivity analysis below, the three parameters 
specifying the $n$th of the eight functions listed above, are denoted $A n, B n$ and $S n$ respectively. Thus $A 3, B 3$ and $S 3$ are the parameters associated with the function $L F M$ with nominal values $1.5,0.7$ and 1.5 respectively.

\section{Numerical sensitivity}

The normalized sensitivity functions

$$
N_{i j}(t)=\left(\partial x_{i} / \partial p_{j}\right) /\left(x_{i} / p_{j}\right)
$$

give the approximate percentage change in the variable $x_{i}$ at time $t$ corresponding to a one percent change in the parameter $p_{j}$ and provide a useful indication of small parameter uncertainty. The nine state variables listed in table 1 as well as Total Revenue were used in this analysis. As the model displays seasonal dynamics, the time during a simulation run at which output is measured will affect the results of a sensitivity analysis. The sensitivity functions were evaluated at monthly intervals during a three year period once the system, operating under the above determined optimal culling rates (kept fixed during the sensitivity analysis), had reached seasonal equilibrium.

\begin{tabular}{|l|c|c|c|}
\hline \multicolumn{1}{|c|}{ Parameter } & Nominal Value & Maximum $N_{i j}$ & State Variable \\
\hline Lynx Fecundity Normal & 0.7 & 2.5341 & $L J$ \\
Ewe Culling Normal & 0.3 & 1.6244 & $S M$ \\
A3 & 1.5 & 1.6125 & $L J$ \\
Sheep Fecundity Normal & 0.75 & -1.3916 & $S M$ \\
Hyrax Juvenile Maturation Normal & 1.0 & -1.1673 & $H J$ \\
Hyrax Units Normal & 700000 & 1.1550 & $H F, H M$ \\
Ilyrax Fecundity Normal & 1.5 & 0.8718 & $H J$ \\
Lynx Female Death Normal & 1.13 & -0.8258 & $L F$ \\
Sheep Male Culling Normal & 0.3 & -0.8083 & $S M$ \\
Lynx Juvenile Death Normal & 0.5 & -0.7313 & $S J$ \\
\hline
\end{tabular}

Table 2.

Maximurn normalized sensitivity function values. 
In table 2 the parameter normal values are listed together with the maximum normalized sensitivity value obtained during the simulation period. The table includes only the ten largest normalized sensitivity function values so obtained. The last column lists the state variable which showed the largest response elasticity. The most sensitive parameter identified in this way is the Lynx Fecundity Normal in which a $1 \%$ increase would lead to a maximum increase of $2.5 \%$ in the state variable Lynx Juvenile at a certain time during the simulation period.

It is interesting to compare the behaviour of normalized sensitivity functions with that of the state variable in which the largest variation occurs for a given parameter.The behaviour of the normalized sensitivity function $N_{i j}$ corresponding to the state variable $S M$ (wethers) and the parameter SFCN (ewe culling normal) over the three year simulation period is illustrated in fig.3.

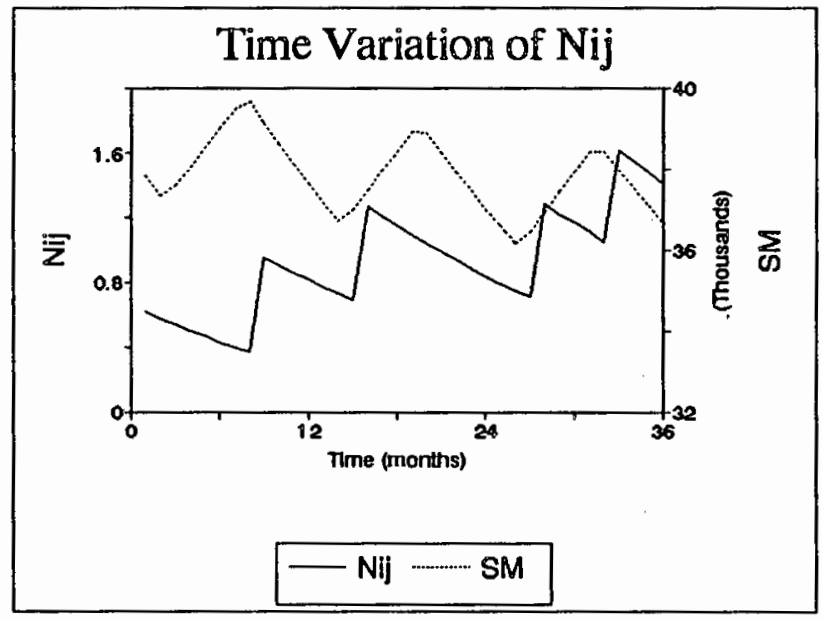

Fig. 3

Behaviour of $\mathrm{N}_{\mathrm{ij}}$ corresponding to state variable SM and parameter SFCN.

The importance of investigating combinations of parameter changes is well known [Vermeulen and De Jongh 1976, Hearne 1985]. The latter derived a method for determining the combination of parameter changes to which the system is most sensitive, subject to a suitable constraint on perturbation magnitude. The 10 largest components of the eigenvector specifying 
the most sensitive direction in parameter space are listed in table 3 . The largest component was assigned the value 100 and the other components scaled accordingly.

\begin{tabular}{|l|c|c|}
\hline \multicolumn{1}{|c|}{ Component } & Relative Value & Perturbation Value \\
\hline Lynx Fecundity Normal & 100.00 & 0.1000 \\
A3 & 50.80 & 0.0508 \\
Lynx Units Normal & 32.67 & 0.0327 \\
Lynx Female Death Normal & -31.30 & -0.0313 \\
Lynx Juvenile Death Normal & -29.03 & -0.0290 \\
Hyrax Fecundity Normal & 24.83 & 0.0248 \\
B3 & -24.60 & -0.0246 \\
A7 & 19.37 & 0.0194 \\
S3 & 17.53 & 0.0175 \\
Lynx Juvenile Maturation Normal & 9.70 & 0.0097 \\
\hline
\end{tabular}

Table 3.

The eigenvector giving the most sensitive direction in parameter space.

\section{Bebavioural sensitivity}

In order to observe the effects of a perturbation along the most sensitive direction on model output, the most sensitive component was perturbed by $10 \%$, other components being perturbed by the appropriate proportional amounts shown in column 3 of table 3 . Thus, for example, the Lynx Juvenile Death Normal ( $L J D N$ ) was decreased by 0.0290 of its nominal value and the parameter $A 3$ associated with the Lynx Fecundity Multiplier function $L F M$, increased by 0.0508 of its nominal value.

The effect of the perturbations on parameters $A 3, B 3$ and $S 3$ on the function $L F M$ is illustrated in fig. 4. Model output as measured, for example by HUT, LUT and SSU remained behaviourally the same as in the standard run as may be seen in figures 5 and 6 . The graph of $H U T$, like that of $S S U$, remains almost identical in the two runs and is not shown. The graph of $L U T$ shows an appreciable upwards shift, but the pattern over time remains the same. The shift is readily understood as virtually every component of the direction eigenvector favours a higher lynx population. The Total Revenue generated over the simulation period changed by only $0.1 \%$. 


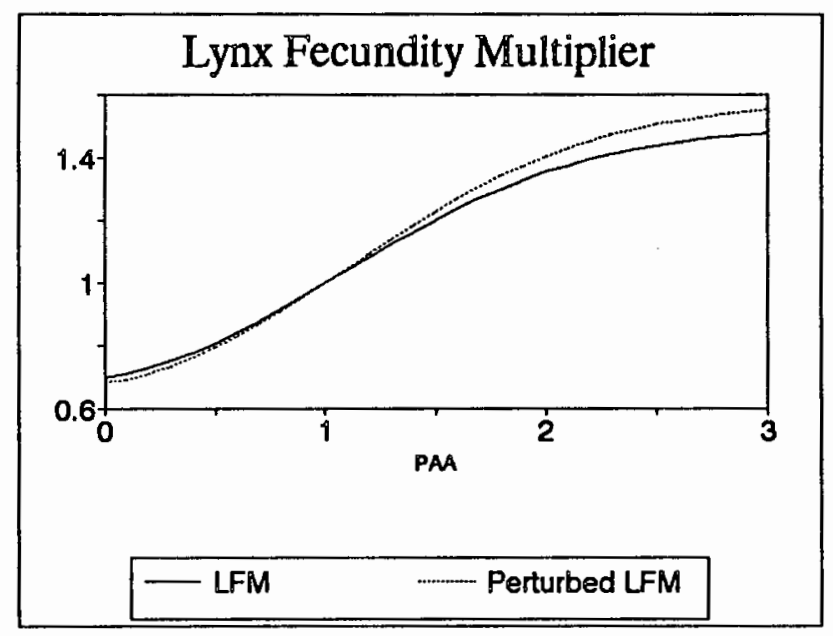

Fig. 4

The standard and perturbed Lynx Fecundity Multipliers.

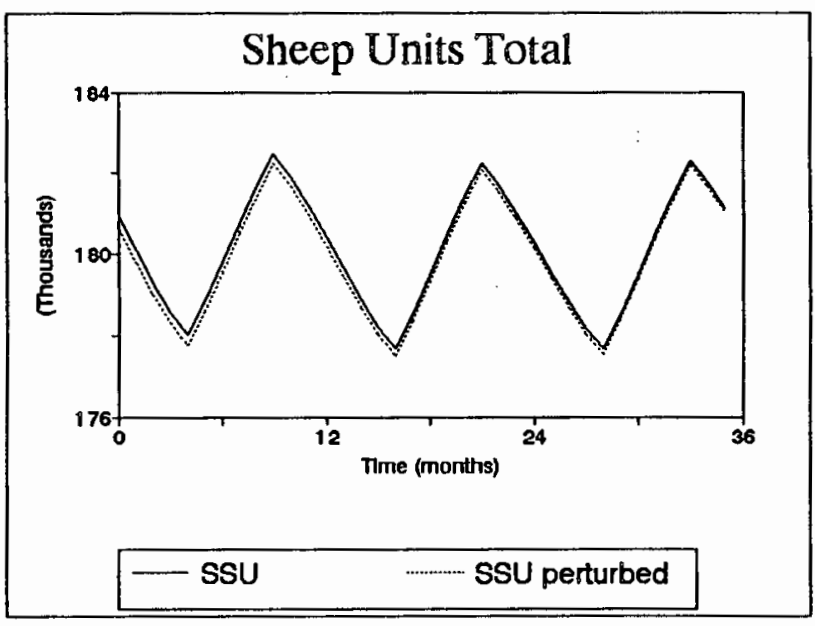

Fig. 5

The effect of parameter variation on sheep. 


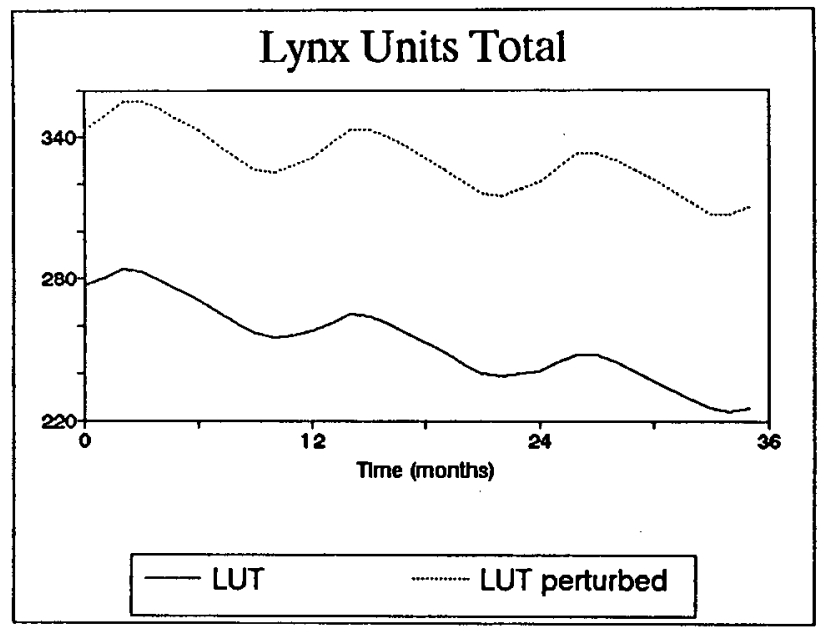

Fig. 6

The effect of parameter variation on lynx.

\section{Policy sensitivity}

In order to implement the optimal culling policy, population numbers are required on a continuing basis and because of the difficulty involved in estimating hyrax and lynx populations [Fourie 1983], it is likely that population counto may be in error by a substantial amount. A policy recommendation for the farmers could be to aim for culling rates of $30 \%$ in both hyrax and lynx, and assuming a worst case error in population counts of $40 \%$, this would mean that actual culling rates may vary between 0.18 and 0.42 . By applying an optimization procedure, the lowest Total Revenue determined by $0.18 \leq H C N, L C N \leq 0.42$ was found to differ from that obtained in the optimal solution by approximately $3 \%$, thus suggesting that the model is quite robust from a policy point of view. By comparing the worst possible outcome of the policy recommendation with the best possible outcome of the farmers' present policy of culling lynx only, the superiority of the simultaneous culling policy is also clearly demonstrated (see table 4). 


\begin{tabular}{|l|c|}
\hline Policy & Revenue generated over 10 years (millions) \\
\hline Optimal & 9.3 \\
\hline Worst cese: & \\
$.18 \leq$ HCN, LCN $\leq .42$ & 9.0 \\
\hline Farmer's best & 8.6 \\
\hline No culling & 7.8 \\
\hline
\end{tabular}

Table 4.

Comparison of culling strategies.

\section{CONCLUSION}

The combination of parameter changes to which the system is most sensitive has been identified and a perturbation along this direction yields similar model behaviour and a new optimal solution not substantially different from the standard one. The model is policy insensitive and in addition seems to be quite robust, at least for small parameter variation, both numerically and behaviourally.

Hyrax fecundity and death normals were derived from data collected in a comprehensive demographic study [Fourie 1983], but the corresponding values for lynx are not as accurately known [Grobler 1981, Fourie 1983]. The Lynx Fecundity Normal has been identified as the most sensitive system parameter. Furthermore, all three parameter values $A 3, B 3, S 3$ specifying the function LFM (Lynx Fecundity Multiplier) appear amongst the top 10 components of the direction eigenvector. More effort by zoologists in determining the lynx parameters more accurately would be well worthwhile.

\section{APPENDIX: Model Equations Listing}

Symbols not defined in the test appear in the symbol list below.

$$
\begin{aligned}
& \text { Hyrax sector } \\
& \frac{d}{d t} H J=H J B-H J D-H J M-H J P
\end{aligned}
$$




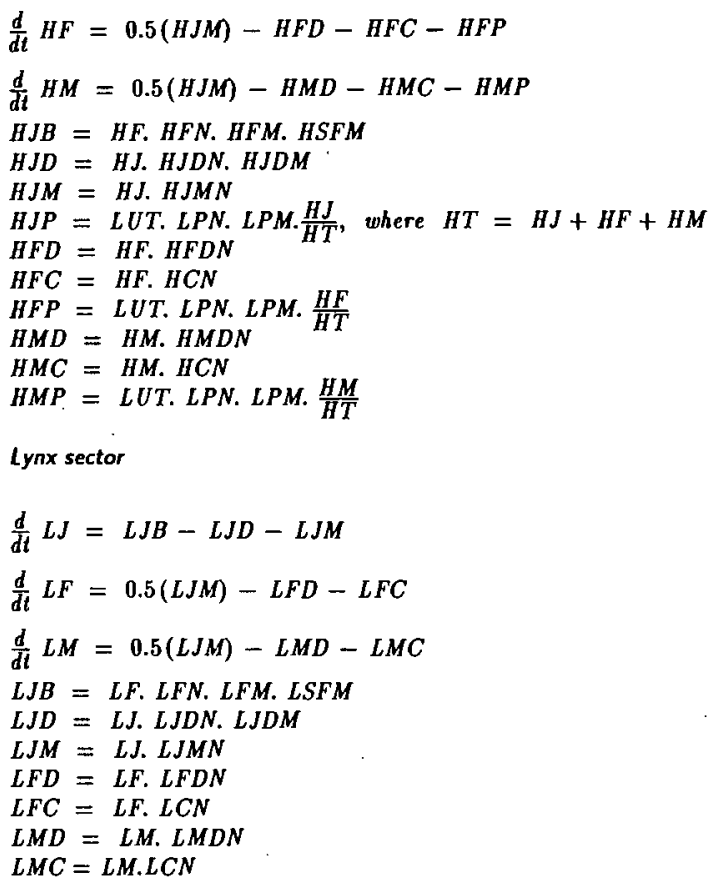

Sheep sector

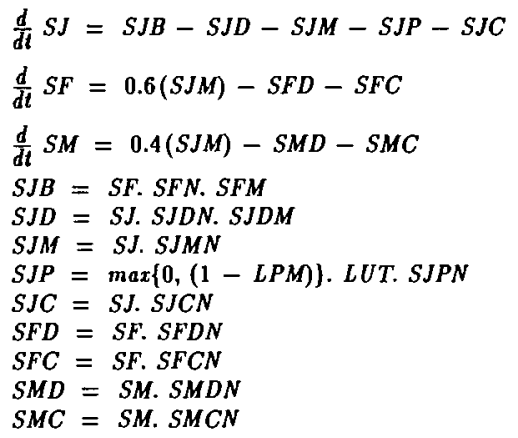




\section{Pasture sector}

$$
\begin{aligned}
& \frac{d P}{d t}=P P-P G \\
& P P=P P N . A R E A . P P M \\
& P G=T S S . G N . G M
\end{aligned}
$$

$T S S U=S S U+\operatorname{mar}\left\{0, \frac{H U T-H U N}{H S}\right\}$

where $B S=$ number of hyrax consuming same amount of pasture as one $S S U$.

Revenue sector

$$
\frac{d}{d t} R E V=M S L S+W S L S+C A P I N T-S C S T-C C S T
$$

$M S L S=S J C . S J M V+S F C . S F M V+S M C . S M M V$

$W S L S=S J . S J W V+S F . S F W V+S M . S M W V$

\begin{tabular}{|c|c|c|}
\hline Name & Symbol & $\begin{array}{c}\text { Units/(function } \\
\text { argument) }\end{array}$ \\
\hline Hyrax Juvenile Birth rate & HJB & hyrax $/ y r$ \\
\hline Hyrax Juvenile Death rate & HJD & hyrax/yr \\
\hline Hyrax Juvenile Maturation rate & НЈМ & hyrax/yr \\
\hline Hyrax Juvenile Predation rate & HJP & hyrax/yr \\
\hline Hyrax Female Death rate & HFD & hyrax/yr \\
\hline Hyrax Female Culling rate & HFC & hyrax/yr \\
\hline Hyrax Female Predation rate & HFP & hyrax/yr \\
\hline Hyrax Male Death rate & HMD & hyrax/yr \\
\hline Hyrax Male Culling rate & HMC & hyrax/yr \\
\hline Hyrax Male Predation rate & HMP & hyrax/yr \\
\hline Hyrax Fecundity Normal & HFN & fraction $/ y r$ \\
\hline Hyrax Fecundity Multiplier & HFM & (HDA) \\
\hline Hyrax Seasonal Fecundity Multiplier & HSFM & (Time-periodic) \\
\hline Hyrax Juvenile Death Normal & HJDN & fraction $/ y r$ \\
\hline Hyrax Juvenile Death Multiplier & HJDM & (IDA) \\
\hline Hyrax Juvenile Maturation Normal & HJMN & fraction $/ y r$ \\
\hline Hyrax Female Death Normal & HFDN & fraction/yr \\
\hline Hyrax Male Death Normal & HMDN & fraction $/ y r$ \\
\hline Hyrax Culling Normal & $\mathrm{HCN}$ & fraction/yr \\
\hline Hyrax Units Normal & HUN & hyrax \\
\hline Hyrax Culling Cost & HCC & Rand/hyrax/yr \\
\hline Hyrax Culling Cost Multiplier & IICCM & ( HD) \\
\hline
\end{tabular}

CAPINT $=$ REV. INT

$S C S T=S J . S J C+(S F+S M) . S C$

$C C S T=(L F C+L M C) \cdot L C C \cdot L C C M+(H F C+H M C) \cdot H C C \cdot H C C M$ 


\begin{tabular}{|c|c|c|}
\hline Name & Symbol & $\begin{array}{c}\text { Unite/(function } \\
\text { argument) }\end{array}$ \\
\hline $\begin{array}{l}\text { Lynx Predation Normal } \\
\text { Lynx Predation Multiplier } \\
\text { Lynx Juvenile Birth rate } \\
\text { Lynx Juvenile Death rate } \\
\text { Lynx Juvenile Maturation rate } \\
\text { Lynx Female Death rate } \\
\text { Lynx Female Culling rate } \\
\text { Lynx Male Death rate } \\
\text { Lynx Male Culling rate } \\
\text { Lynx Fecundity Normal } \\
\text { Lynx Fecundity Multiplier } \\
\text { Lynx Seasonal Fecundity Multiplier } \\
\text { Lynx Juvenile Death Normal } \\
\text { Lynx Juvenile Death Multiplier } \\
\text { Lynx Juvenile Maturation Normal } \\
\text { Lynx Female Death Normal } \\
\text { Lynx Culling Normal } \\
\text { Lynx Male Death Normal } \\
\text { Lynx Culling Cost } \\
\text { Lynx Culling Cost Multiplier }\end{array}$ & $\begin{array}{l}\text { LPN } \\
\text { LPM } \\
\text { LJB } \\
\text { LJD } \\
\text { LJM } \\
\text { LFD } \\
\text { LFC } \\
\text { LMD } \\
\text { LMC } \\
\text { LFN } \\
\text { LFM } \\
\text { LSFM } \\
\text { LJDN } \\
\text { LJDM } \\
\text { LJMN } \\
\text { LFDN } \\
\text { LCN } \\
\text { LMDN } \\
\text { LCC } \\
\text { LCCM }\end{array}$ & $\begin{array}{l}\text { hyrax/lynx/yr } \\
\text { (PA) } \\
\text { lynx } / y r \\
\text { lynx/yr } \\
\text { lynx/yr } \\
\text { lynx/yr } \\
\text { lynx/yr } \\
\text { lynx } / y r \\
\text { lynx/yr } \\
\text { fraction } / y r \\
\text { (PAA) } \\
\text { (Time-periodic) } \\
\text { fraction } / y r \\
\text { (PAA) } \\
\text { fraction } / y r \\
\text { fraction } / y r \\
\text { fraction } / y r \\
\text { fraction } / y r \\
\text { Rand } / \text { lynx } / y r \\
\text { (Lynx Density) }\end{array}$ \\
\hline $\begin{array}{l}\text { Sheep Juvenile Birth rate } \\
\text { Sheep Juvenile Death rate } \\
\text { Sheep Juvenile Maturation rate } \\
\text { Sheep Juvenile Predation rate } \\
\text { Sheep Juvenile Culling rate } \\
\text { Sheep Female Death rate } \\
\text { Sheep Female Culling rate } \\
\text { Sheep Male Death Rate } \\
\text { Sheep Male Culling rate } \\
\text { Sheep Fecundity Normal } \\
\text { Sheep Fecundity Multiplier } \\
\text { Sheep Juvenile Death Normal } \\
\text { Sheep Juvenile Death Multiplier } \\
\text { Sheep Juvenile Maturation Normal } \\
\text { Sheep Juvenile Predation Normal } \\
\text { Sheep Juvenile Culling Normal } \\
\text { Sheep Female Death Normal } \\
\text { Sheep Female Culling Normal } \\
\text { Sheep Male Death Normal } \\
\text { Sheep Male Culling Normal } \\
\text { Sheep Juvenile Meat Value } \\
\text { Sheep Female Meat Value } \\
\text { Sheep Male Meat Value } \\
\text { Sheep Juvenile Wool Value } \\
\text { Sheep Female Wool Value } \\
\text { Sheep Male Wool Value } \\
\text { Sheep Juvenile Cost } \\
\text { Sheep Cost }\end{array}$ & $\begin{array}{l}\text { SJB } \\
\text { SJD } \\
\text { SJM } \\
\text { SJP } \\
\text { SJC } \\
\text { SFD } \\
\text { SFC } \\
\text { SMD } \\
\text { SMC } \\
\text { SFN } \\
\text { SFM } \\
\text { SJDN } \\
\text { SJDM } \\
\text { SJMN } \\
\text { SJPN } \\
\text { SJCN } \\
\text { SFDN } \\
\text { SFCN } \\
\text { SMDN } \\
\text { SMCN } \\
\text { SJMV } \\
\text { SFMV } \\
\text { SMMV } \\
\text { SJWV } \\
\text { SFWV } \\
\text { SMWV } \\
\text { SJC } \\
\text { SC } \\
\end{array}$ & $\begin{array}{l}\text { sheep/yr } \\
\text { sheep/yr } \\
\text { sheep/yr } \\
\text { sheep/yr } \\
\text { sheep/yr } \\
\text { sheep/yr } \\
\text { sheep/yr } \\
\text { sheep/yr } \\
\text { sheep/yr } \\
\text { fraction/yr } \\
\text { (GMA) } \\
\text { fraction/yr } \\
\text { (GMA) } \\
\text { fraction/yr } \\
\text { lambs/lynx/yr } \\
\text { fraction/yr } \\
\text { fraction/yr } \\
\text { fraction/yr } \\
\text { fraction } / y r \\
\text { fraction/yr } \\
\text { Rand/lamb } / y r \\
\text { Rand/sheep/yr } \\
\text { Rand/sheep/yr } \\
\text { Rand/lamb } / y r \\
\text { Rand/sheep/yr } \\
\text { Rand/sheep/yr } \\
\text { Rand/lamb } / y r \\
\text { Rand/sheep/yr }\end{array}$ \\
\hline
\end{tabular}




\begin{tabular}{|c|c|c|}
\hline Name & Symbol & $\begin{array}{c}\text { Units/(function } \\
\text { argument) }\end{array}$ \\
\hline $\begin{array}{l}\text { Pasture } \\
\text { Pasture Production } \\
\text { Pasture Grazed } \\
\text { Pasture Production Normal } \\
\text { Area } \\
\text { Pasture Production Multiplier } \\
\text { Total Small Stock Units } \\
\text { Grazing Normal } \\
\text { Grazing Multiplier } \\
\text { Revenue } \\
\text { Meat Sales } \\
\text { Wool Sales } \\
\text { Interest on Capital } \\
\text { Sheep Cost } \\
\text { Culling Cost } \\
\text { Interest rate }\end{array}$ & $\begin{array}{l}\text { P } \\
\text { PP } \\
\text { PG } \\
\text { PPN } \\
\text { AREA } \\
\text { PPM } \\
\text { TSSU } \\
\text { GN } \\
\text { GM } \\
\text { REV } \\
\text { MSLS } \\
\text { WSLS } \\
\text { CAPINT } \\
\text { SCST } \\
\text { CCST } \\
\text { INT }\end{array}$ & $\begin{array}{l}\text { grazing days } \\
\text { grazing days/yr } \\
\text { grazing days/yr } \\
\text { grazing days } \\
\text { /yr/ha } \\
\text { ha } \\
\text { (Time-periodic) } \\
\text { small stock units } \\
\text { grazing days } \\
\text { /yr } / \mathrm{SSU} \\
\text { (PAI) } \\
\text { Rand } \\
\text { Rand/yr } \\
\text { Rand/yr } \\
\text { Rand/yr } \\
\text { Rand } / y r \\
\text { Rand/yr } \\
\text { fraction } / y r\end{array}$ \\
\hline
\end{tabular}

\section{ACKNOWLEDGEMENT}

This work was supported by the University of Natal Research Fund.

\section{REFERENCES}

Abstract of Agricultural Statistics, Republic of South Africa, 1986.

Antrobus, G.G., The economic importance and environmental impact of domestic stock. Paper presented at the Symposium: Towards an Environmental Plan for the Eastern Cape, Rhodes University, Grahamstown, July 1983.

Bradfield, R.E.D. and H.H. Barnard, The animal husbandry situation in the Reasonable Homogeneous Ecological Areas (RIIEA's) of the Eastern Cape Region. Report OK-Do 92/1, Agricultural Research Station, Dohne, 1981. 
Danckwertz, J.E., A technique to assess the grazing capacity of sweetveld with particular reference to the False Thornveld of the Ciskei. M.Sc. Agric. Thesis, University of Natal, Pietermaritzburg, 1981.

Fairall, N., Growth and age determination in the hyrax Procavia capensis, S. Afr. J. Zool., 15, $16-21,1980$.

Fourie, L. J., The population dynamics of the rock hyrax Procavia capensis (Pallas, 1766) in the Mountain Zebra National Park. Ph.D. Thesis, Rhodes University, Grahamstown, 1983.

Grobler, J.H., Feeding behaviour of the caracal Felis caracal (Schreber, 1766) in the Mountain Zebra National Park, S. Afr. J. Zool., 16, 259-262, 1981.

Hearne J.W., Sensitivity analysis of parameter combinations, Appl. Math Modelling, 9, 106-108, 1985.

Stuart, C. Aspects of the biology of the caracal Felis caracal (Schreber, 1776) in the Cape Province, South Africa. M.Sc. Thesis, University of Natal, Pietermaritzburg, 1982.

Swart, J. and J.W. Hearne, A mathematical model to analyse predation and competition problems in a sheep farming region, System Dynamics Review, 5, 35-50, 1989.

Swart, J., A system dynamics approach to predator-prey modelling, System Dynamics Review, 6, (no.1, Winter 1990).

Tainton, N.M., Veld and pasture management in South Africa, Shuter and Shooter in association with University of Natal Press, Pietermarizburg.

Uys, P.W., An analytical form for Table Functions used in Systems Dynamics, Dynamica, 10, $81-83,1984$.

Vermeulen, P.J., and D.C. de Jongh, Parameter sensitivity of the 'Limits to growth' world model, Appl. Math. Modelling, 1, 29-32, 1976. 